\title{
As transformações do capitalismo contemporâneo e seus impactos na periferia: uma interpretação sobre a crise brasileira recente
}

\author{
The transformations in contemporary capitalism \\ and its impacts on the periphery: an interpretation \\ of the recent Brazilian crisis
}

DOI: $10.21530 /$ ci.v15n1.2020.1009

Valéria Lopes Ribeiro ${ }^{1}$

\section{Resumo}

Este trabalho apresenta uma interpretação sobre as transformações do capitalismo contemporâneo e em que medida estas mudanças vêm influenciando as trajetórias de crescimento e desenvolvimento das economias periféricas nos anos recentes, mais especificamente, a economia brasileira. O objetivo do estudo é analisar como as transformações estruturais do capitalismo contemporâneo se uniram às contradições de ordem interna, ligadas a políticas macroeconômicas e tensões resultantes do conflito distributivo para, a partir daí, interromper a trajetória de crescimento vivenciada pelo Brasil entre 2004 e 2011. A hipótese do trabalho é de que, embora os aspectos internos sejam fundamentais para a compreensão da crise, eles devem se aliar a interpretação mais ampla, que leve em consideração o atual momento do capitalismo contemporâneo. Esta hipótese será desenvolvida a partir da análise de mudanças observadas na economia internacional ao longo das últimas décadas, ligadas ao acirramento das contradições do modo de produção capitalista e ao acirramento das disputas interestatais.

Palavras-chave: Capitalismo contemporâneo; Crise; Economia Política Internacional; Brasil.

\section{Abstract}

The paper presents an interpretation of the transformations of contemporary capitalism and the extent to which these changes have influenced the growth and development trajectories

1 Professora Adjunta do Bacharelado em Relações Internacionais e do Bacharelado em Economia da Universidade Federal do ABC (UFABC). Professora permanente dos Programas de Pós-Graduação em Economia Política Mundial (EPM/UFABC) e da Pós- Graduação em Relações Internacionais (PRI/UFABC). Doutora em Economia Política Internacional pelo Programa de Pós-Graduação em Economia Política Internacional da Universidade Federal do Rio de Janeiro (UFRJ). ORCID: http://orcid.org/0000-0003-3885-4805; email: valeria.ribeiro@ufabc.edu.br Artigo submetido em 19/09/2019 e aprovado em 09/03/2020. 
of peripheral economies in recent years, more specifically, the Brazilian economy. The aim of the study is to analyze how the most structural transformations of contemporary capitalism have joined internal contradictions linked to macroeconomic policies and tensions resulting from the distributive conflict, thereby interrupting the growth trajectory experienced by Brazil between 2004 and 2011. The hypothesis of the paper is that while internal aspects are fundamental in understanding the crisis, they must be combined with a broader interpretation that takes into account the current moment of contemporary capitalism. This hypothesis will be developed from the analysis of the changes observed in the international economy over the last decades linked to the intensification of the contradictions of the capitalist mode of production and the intensification of interstate disputes.

Keywords: Contemporary capitalism; Crise; International political economy; Brazil.

\section{Introdução}

Entre 2003 e 2011 o Brasil vivenciou período de crescimento econômico que se refletiu na melhora de diversos indicadores, como renda e emprego. A taxa média de crescimento do PIB nesse período foi de 4,06\% ao ano (World Bank Database, 2020) e o número de empregos formais cresceu 53,6\% entre 2003 e 2010. (Guimarães 2012).

As razões que explicam o período de prosperidade foram amplamente debatidas e, ainda que com diferentes ênfases, podem ser relacionadas a aspectos como: conjuntura internacional de termos de troca favoráveis para as periferias, aliada ao barateamento dos fluxos de capitais internacionais; melhora do quadro macroeconômico nacional que resultou desta conjuntura; as políticas de expansão do investimento estatal; as políticas de estímulo à demanda interna, via expansão do salário real e políticas de transferência de renda. (Corrêa e Dos Santos 2013; Pochmann 2012; Medeiros 2015).

Ponto importante deste período de crescimento brasileiro é que ele não foi um caso isolado. Países da América Latina, África e Ásia, também observaram quadro de crescimento econômico ${ }^{2}$. Segundo Nayyar (2014), este crescimento recente dos países "em desenvolvimento" reflete mudança histórica, de ampliação

2 De acordo com WorldBank Database 2020, na primeira década do século XXI o continente africano cresceu a quase $5 \%$ na década e a África Subsaariana cresceu a uma taxa de 5,5\% ao ano. No mesmo período, a China apresentou taxa média de crescimento do PIB de cerca de $10 \%$ ao ano entre 2000 e 2012. Mesmo com a crise econômica de 2008, o país seguiu crescendo a taxas altas (10,4\% em 2010, 9,2\% em 2011 e 7,8\% em 2012), em trajetória de crescimento que já dura mais de 30 anos. (WorldBank Database 2020). 
da sua participação no produto global. Para o autor, desde o final do século XX se assiste a uma espécie de "convergência. ${ }^{3}$

Apesar da expansão econômica observada na primeira década do século XXI, a partir de 2010 e, principalmente a partir de 2012, observou-se, no caso brasileiro, interrupção do processo de expansão do PIB, movimento que também pôde ser observado em outros países. A partir de 2011 a taxa de crescimento do PIB brasileiro caiu de 7,5\% para 3,98\% e para 1,93\% em 2012 (WorldBank Database 2020 ). De 2011 a 2017 a taxa média de crescimento do Brasil foi de apenas $0,4 \%$ ao ano.

Desde 2011 vive-se no Brasil um período de crise econômica e política, cujas interpretações ganharam diversas dimensões, seja no campo da economia política crítica, seja entre economistas ortodoxos e cientistas políticos. Boa parte destas análises se volta para aspectos internos que teriam levado à crise, tais como: erros de política macroeconômica levados adiante pela equipe econômica do governo Dilma Rousseff (Carvalho, 2018); conflito distributivo interno gerado pelo crescimento (Serrano e Summa, 2018); ou ainda disputa entre frações da burguesia que teriam rompido uma espécie de pacto de classes anterior (Boito Jr, 2018).

Em trabalhos como os de Carvalho (2018) é possível observar análise das causas da crise ligadas às tentativas fracassadas do governo Dilma Rousseff de estimular a economia, via incentivos à indústria, desonerações e intervenções no câmbio e, a partir de 2014, um ajuste fiscal extremamente contraproducente para a economia. Tais medidas são consideradas fruto de "erro de diagnóstico" (Carvalho, 2018). Também em Serrano e Summa (2018) encontra-se interpretação da estagnação brasileira baseada na ideia de que o crescimento gerou uma espécie de 'revolução indesejada' no mercado de trabalho entre 2004 e 2014, ao aumentar o poder de barganha dos trabalhadores - com os salários reais crescendo acima da produtividade - acirrando o conflito distributivo e a queda da margem de lucro das empresas.

3 Segundo o autor, a partir dos dados de Maddisson, em preços correntes e à taxa de câmbio de mercado, entre 1970 e 2010 a participação dos países em desenvolvimento no PIB mundial dobrou de 1/6 para 1/3. (Nayyar 2014). É fundamental esclarecer que a chamada "convergência” pode ser bastante questionada, na medida em que a melhora foi extremamente desigual no grupo dos países em desenvolvimento. Outra questão é que a melhora foi puxada fundamentalmente pela Ásia, e pela China em particular, e não se refletiu em grandes transformações em termos de renda per capita. Outro ponto é que, em países da América Latina e África, o crescimento foi bem mais modesto ou inexistente, refletido em aumento da participação no comércio global e não em termos de industrialização, por exemplo. 
Tais análises foram e são fundamentais no entendimento da crise brasileira. Ainda assim, neste trabalho procuramos argumentar que tais análises desconsideram elementos fundamentais, relacionados às transformações do capitalismo contemporâneo e das relações interestatais.

Como sugere Medeiros (2010), em boa parte dos estudos críticos se pode observar predomínio do que Gore (1996 apud Medeiros, op. cit.) denominou de nacionalismo metodológico, em que a nação é referida como unidade autossuficiente e inserida em ambiente internacional indiferenciado.

Ainda que autores de diferentes vertentes, como Prebisch (2000) e, também, a teoria de dependência (de forma distinta) tentassem superar esses limites com relação aos pioneiros do desenvolvimento ${ }^{4}$ (e com relação à própria Cepal, no caso da teoria da dependência), a depender da conjuntura histórica, favorável ou não ao desenvolvimento endógeno, a análise centrada em um excessivo nacionalismo metodológico sempre volta à tona.

No sentido de avançar uma análise que fuja do nacionalismo metodológico, o objetivo deste trabalho é contribuir para o debate sobre a crise brasileira recente, a partir da investigação da inserção do país em uma conjuntura específica do capitalismo mundial e suas repercussões na dinâmica interestatal. Nossa hipótese está relacionada à ideia de que, para além da própria crise de 2008, o capitalismo passa por mudanças ligadas ao acirramento de contradições fundamentais, principalmente nas economias centrais e a partir da emergência de novos países, como a China.

O artigo está dividido da seguinte forma: além da Introdução, na seção 2 serão discutidas as transformações do capitalismo mundial e as contradições do processo de acumulação; na seção 3 são apresentados os impactos destas transformações de ordem econômica e estrutural no aumento da competição interestatal; na seção 4 procuraremos identificar como estas mudanças influenciaram a crise brasileira; a seção 5 traz as conclusões.

4 Os chamados "pioneiros" do Desenvolvimento são autores que, a partir dos anos 1950, iniciaram os debates em torno da Teoria do Desenvolvimento, entre eles Ragnar Nurkse, Rosenstein-Rodan e Arthur Lewis. (Agarwala e Singh 2010) 


\section{Transformações no capitalismo internacional}

Após mais de dez anos desde a crise de $2007-2008^{5}$, a economia mundial ainda não conseguiu apresentar grandes patamares de crescimento. Mesmo nas economias avançadas se observa um quadro de baixo crescimento e dificuldade em expandir níveis de renda (Gráfico 1).

\section{Gráfico 1 - Taxa de crescimento do PIB mundial, da América do Norte e da Área do Euro (eixo direito); Taxa de crescimento do PIB per capita mundial (dólares/eixo esquerdo) (2005-2018)}

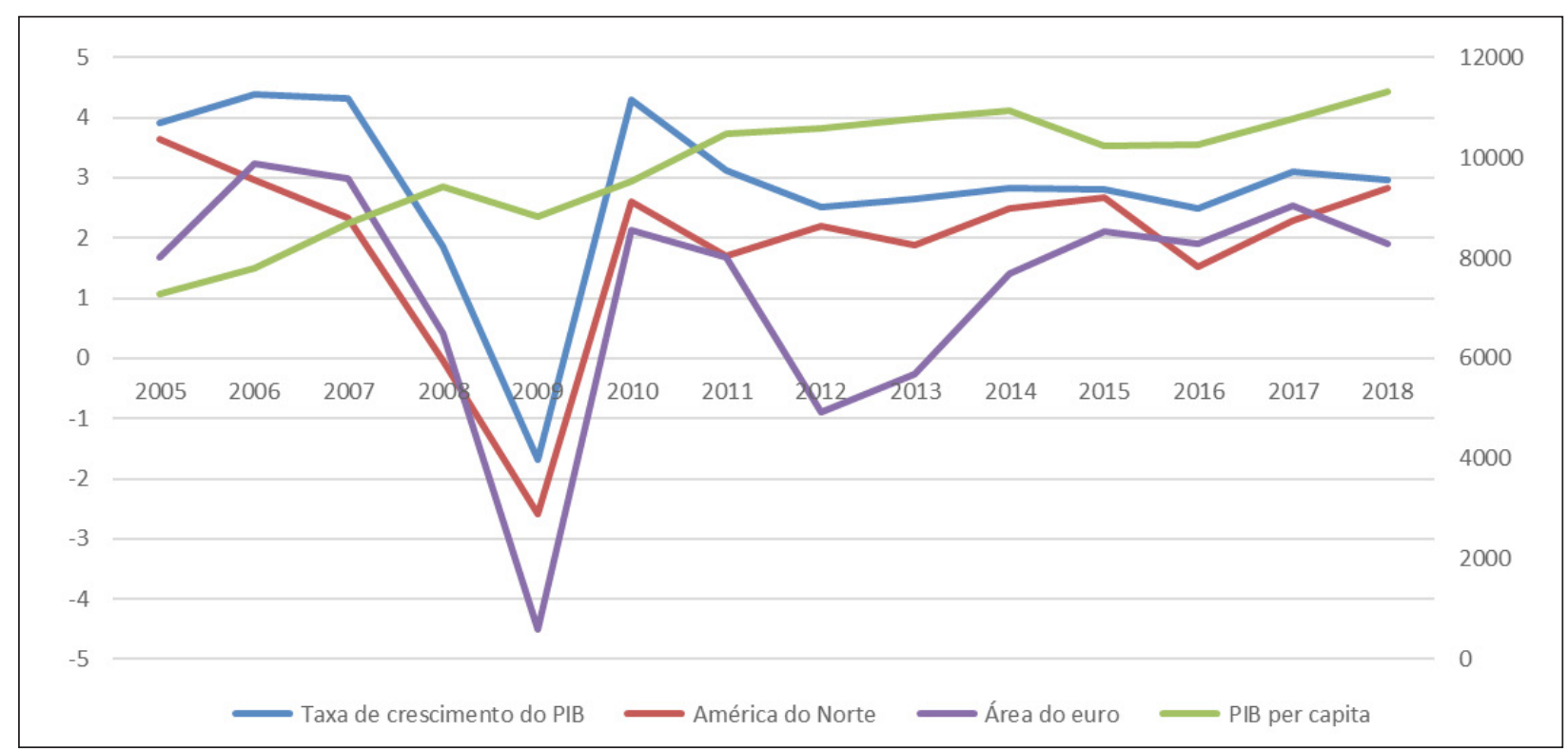

Fonte: World Bank Database, 2020.

A dificuldade de retomada de maiores patamares de crescimento a níveis mundiais, aliada a intensificação das contradições sociais, tem suscitado diversas interpretações sobre as causas da crise recente, suas determinações e características. Para diversos autores, tal crise estaria ligada a caraterísticas observadas em diversos países desde os anos 70, tais como: forte expansão dos instrumentos de acumulação financeira ${ }^{6}$ (Chesnais 2016); acentuada queda da taxa de lucro,

5 A crise de 2007/2008 refletiu contradições do sistema financeiro norte-americano, especificamente a especulação no mercado imobiliário. A supervalorização feita pelas agências de classificação de risco aliada à desregulamentação do mercado, levam a formação de uma bolha no mercado de imobiliário, com a inserção do chamados subprime. O objetivo do artigo não é analisar a crise de 2008 em si, mas sua relação com um processo de crise mais amplo e estrutural. Para mais detalhes sobre a crise ver, por exemplo, Torres Filho 2014.

6 Como aponta Chesnais, nos últimos anos o aumento do volume de ativos financeiros como porcentagem do PIB mundial foi expressivo. Segundo o autor, o volume de ativos financeiros cresceu a uma taxa média anual composta de $9 \%$ entre 1990 e 2007, com acentuada aceleração em 2006 e 2007 ( + 18\%). Naquele ano, a proporção de ativos como porcentagem do PIB mundial subiu para 359\%. (Chesnais 2016, 37). 
evidenciando a tendência descrita por Marx no Livro 3 de O Capital7 (Kliman 2015); crise do padrão de acumulação do tipo fordista e transição para um padrão flexível (Harvey 1992); ou, ainda, estabelecimento do padrão monetário dólar-flexível ligado à retomada da hegemonia norte-americana (Tavares 1985).

Para Streeck (2018), a mais recente crise do capitalismo deve ser entendida como continuidade da crise dos anos 70, quando os capitalistas teriam rompido de forma brutal o processo de expansão produtiva iniciado no pós Segunda-Guerra, na medida em que esse modelo se tornava caro demais. Segundo o autor, àquela altura, uma kaleckiana ${ }^{8}$ greve dos investimentos teria sido a razão fundamental da crise, representada por uma ação coordenada entre empresas e empresários que conseguiram se organizar coletivamente em torno da crítica ao "excesso de emprego e regulação" (Streeck 2018).

Assim, Streeck afirma que a recente crise do capitalismo, ocorrida em 2007 e 2008, deve ser entendida como continuidade daquele processo de dissolução do regime do capitalismo do pós-guerra. Ou seja, aquela crise, ao invés de ter sido resolvida, foi apenas adiada. Esse adiamento se deu mediante: "a inflação; depois pelo endividamento do Estado; a seguir, pela expansão dos mercados de crédito privados; e, por fim, atualmente, pela compra de dívidas de Estados e de bancos pelos bancos centrais”. (Streeck, op. cit, pg. 28). Essas tentativas de adiamento da crise, por sua vez, contribuem para expandir os mecanismos de acumulação financeira, gerando novos elementos de crise.

Desse modo, uma espécie de adiamento da crise é justamente a raiz da crise de 2007-2008. Ou seja, os próprios mecanismos utilizados para lidar com a crise, via endividamento, por exemplo, geraram efeitos de acumulação financeira que, em determinado momento, explodiram na forma de bolhas, como no caso da crise do mercado imobiliário norte americano.

Esta visão apresentada por Streeck remete à passagem fundamental do Livro 3 de O Capital (Marx, 1984), lembrada por Chesnais (2016), que afirma: “A produção

7 A lei da queda tendencial da taxa de lucro, a partir de Marx (1984), deve ser analisada levando em consideração suas contra tendências, ou seja, mecanismos adotados de forma a compensar a queda tendencial da taxa de lucro. Dessa forma, a lei em si não garante a queda da taxa de lucro, dadas as contra tendências. Como ressalta Kliman (2015) essa tendência não leva a um estado estacionário, mas sim à formação de ciclos de crescimento e queda, não podendo ser, nesse sentido, a causa direta das desacelerações, mas sim indireta, já que reduz a disposição dos capitalistas para investir na esfera da produção.

8 Streeck se refere ao economista Michal Kalecki, que discute, na famosa palestra intitulada "Aspectos políticos do pleno emprego" (Kalecki 1944), a importância de se considerar o crescimento econômico como estimulado ou interrompido por ações políticas, conduzidas por interesses de grupos, como empresários, que atuam no sentido de atingir seus objetivos, por exemplo, pressionando pela redução de salário. 
capitalista busca continuamente superar suas barreiras imanentes, mas supera-as apenas por meios que estabelecem as barreiras novamente e em uma escala mais poderosa” (Marx, 1981, Vol. III, p. 358. apud Chesnais, 2016).9

Em análise similar à de Streeck, Choonara (2018) afirma que a contradição fundamental da crise dos anos 1970, qual seja, a queda da lucratividade, não foi resolvida, mas sim contornada, mediante a ação do Estado e sua relação com o capital. Segundo este autor, ao contrário das crises anteriores do capitalismo, que promoviam um aniquilamento violento do capital com vistas a retomar o ponto de expansão, a atual concentração e centralização do capital e os riscos de uma nova crise levam os Estados a "salvar" o capital, via empréstimos e financiamento de grandes bancos, fazendo com que não haja "limpeza” das unidades não lucrativas. Com isso se verificam contrações menos bruscas, mas, ao mesmo tempo, observase o que se denomina "grande moderação", ou seja, crescimento mais lento, além de novas formas de manter a rentabilidade via financeirização e busca de novos espaços de acumulação.

Já para Chesnais (2016), a crise recente do capitalismo não pode ser interpretada como ligada a uma situação de "grande moderação", ou como "crise da financeirização", isto porque, segundo o autor, trata-se de uma crise do "capitalismo tout court” (pp. 1-2), isto é, uma crise mais profunda de sobreacumulação e superprodução. (Chesnais 2016).

A posição de Chesnais se insere em análise mais ampla do autor sobre as características fundamentais do capitalismo contemporâneo. Segundo ele, existem duas dimensões fundamentais do capitalismo atual: a primeira seria o chamado "finance capital", ou seja, forte entrelaçamento entre bancos globais internacionalizados e altamente concentrados, com grandes indústrias transnacionais e corporações de serviços e gigantes varejistas, que caracterizam e moldam o capitalismo recente; a segunda dimensão é a expansão contínua dos instrumentos de acumulação financeira em si, ou seja, ações, derivativos, bonds, etc.

A partir destas dimensões, a crise recente do capitalismo não seria ligada apenas à expansão dos instrumentos de acumulação financeira em detrimento da expansão produtiva, mas ao momento em que as condições dadas pelo "finance capital” instauram uma crise de sobreacumulação e superprodução. Isto porque as condições geradas pelo "finance capital” impõem condições macroeconômicas

9 "Capitalist production seeks continually to overcome its immanent barriers, but overcomes them only by means that set up the barriers afresh and on a more powerful scale" (Marx 1981, Vol. III, p. 358. apud Chesnais, 2016). 
que moldam as relações de poder entre capital e trabalho em favor do primeiro. A partir daí impede-se que o total de mais valia produzida globalmente seja realizada, fazendo com que o capital se depare com um bloqueio no processo de acumulação, e não complete seu circuito. Esta é a raiz da crise de sobreacumulação e superprodução. (Chesnais 2016).

Para Chesnais, esta crise de sobreacumulação e superprodução teria sido criada desde a metade dos anos 1990 e adiada ao longo destes anos apenas pela massiva criação de crédito na economia americana e europeia e, ainda, pela incorporação da China na economia mundial, que deram um folego momentâneo à crise.

Carcanholo (2011) também observa o capitalismo contemporâneo a partir de suas contradições ligadas à dinâmica do capital fictício. Segundo este autor, no capitalismo contemporâneo massa crescente de capital se especializa na mera apropriação de valor, que não é produzido na mesma magnitude, prevalecendo a disfuncionalidade do capital fictício para o modo de produção capitalista. A nova crise estrutural do capital diz respeito a essa disfuncionalidade do capital fictício, na medida em que a apropriação do valor não é compatível com a produção de valor.

A crise atual do capitalismo (a crise no mercado mobiliário norte-americano e a crise de 2008) não se relaciona apenas à expansão do capital fictício em si, ou ao processo de financeirização, mas à relação deste com a produção e geração de valor (ou não geração de valor) no que podemos chamar de economia real. Assim, "a nova crise estrutural do capitalismo, neste início de século XXI, se explica justamente pelo predomínio da disfuncionalidade da lógica do capital fictício para a acumulação do capital total." (Carcanholo 2011)

A partir de Carcanholo (op. cit.) e Chesnais (op. cit.), a nosso ver, a nova crise do capitalismo refletiria, de fato, um desdobramento de suas contradições imanentes, situadas em uma determinação histórica específica, marcado por amplo descolamento entre a apropriação do valor e a geração de valor. nosso ver, a uma determinação histórica fundamental. Essa determinação estaria relacionada a profunda alteração da divisão internacional do trabalho, marcada pela corrida do capital para locais de produção fora das tradicionais localidades das economias centrais, em regiões principalmente da Ásia, promovendo ampliação da geração de valor a partir de algumas regiões do Sul, notadamente a Ásia e principalmente a China.

Nesse sentido, como aponta Chesnais (2016), a entrada da China correspondeu a um movimento que deu folego ao processo de acumulação, mas, mais do que 
isso, ela representa condição histórica fundamental que acentuou as contradições ligadas ao capitalismo contemporâneo e à disfuncionalidade do capital fictício.

Ao longo de 1980 e 1990, de fato, a entrada da China foi funcional ao processo de acumulação no centro, na medida em que representou, principalmente, a possibilidade de expandir a apropriação de valor, contornando em parte a queda da lucratividade, com ampliação da remessa de lucros e utilização de mão de obra barata para a produção. No entanto, no século XXI, observa-se disfuncionalidade desse processo para a acumulação de capital no centro, na medida em que países, principalmente a China, ampliam sua parcela na geração e apropriação do valor, como mostra o Gráfico 2, através de processo de acumulação de capital marcado, não apenas pela presença de empresas estrangeiras que remetem lucros, mas também, e cada vez mais, por empresas domésticas nacionais que promovem expansão econômica sem precedentes, com ganhos de produtividade e expansão da renda interna. (Ribeiro e Paraná 2019).

\section{Gráfico 2 - China: Participação do PIB da China no PIB mundial (a) e Valor agregado doméstico nas exportações brutas ${ }^{10}$ (b)}

(a)

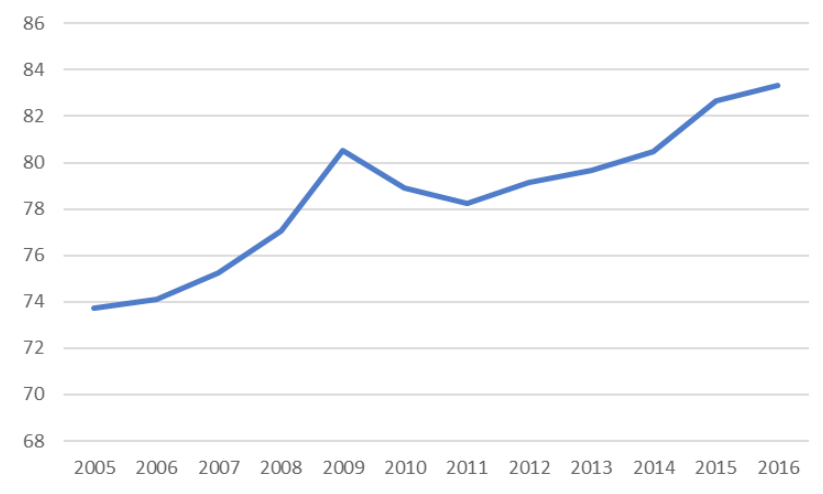

(b)

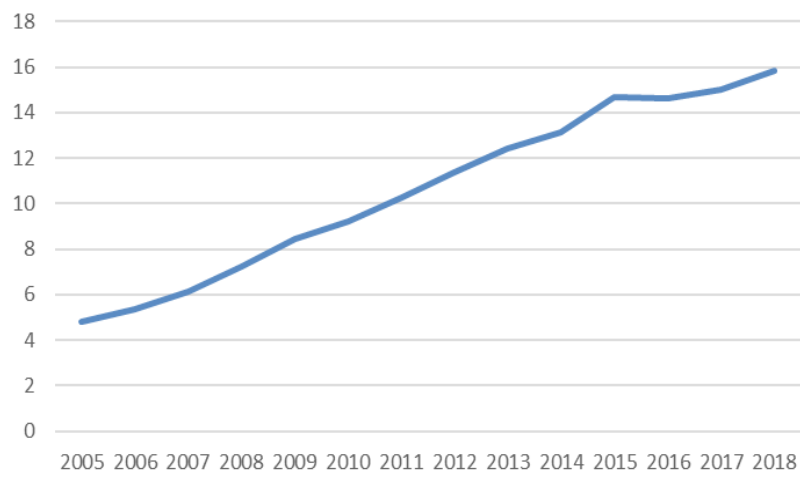

Fonte: WorldBank Database, 2020; OECD DATA, 2020.

\section{Acirramento da competição interestatal}

Se em determinado momento o deslocamento produtivo do capital para novas áreas de valorização foi funcional à tentativa de superação da crise da acumulação,

10 O valor adicionado doméstico nas exportações brutas é uma estimativa do valor adicionado, por uma economia, na produção de bens e serviços para exportação, definida simplesmente como a diferença entre a produção bruta a preços básicos e o consumo intermediário a preços de compradores. A medida é uma participação percentual do valor. (OECD, 2020). 
atualmente esse movimento contribui para acirrar as contradições e exacerbar a competição interestatal. De fato, o acirramento da competição interestatal recente resulta de momento específico do capitalismo contemporâneo, marcado pelo aprofundamento da crise e seu eterno adiamento.

O período pós-crise de 2008 foi marcado por alguns movimentos como: resgate dos grandes bancos por parte dos bancos centrais; flexibilização quantitativa1"; adoção de taxas de juros baixas ou mesmo negativas nas economias centrais. Apesar destas medidas manterem o capitalismo vivo, elas não tiveram efeito significativo na retomada da produção nos países centrais. A rentabilidade baixa, ou a "grande moderação", permanece como caraterística fundamental do capitalismo contemporâneo, fazendo com que os capitalistas não retomem seus investimentos e, com isso, não se consiga expandir os níveis de emprego e renda.

Quanto mais a crise se acirra nos países centrais, maior tende a ser a continuidade das tentativas de superação, não por meio de mudança profunda na forma de acumulação, mas por meio da acentuação das contradições. Assim poderíamos pensar no aumento da taxa de exploração do trabalho sob a forma de diminuição de salários, retirada de direitos, precarização, ou ainda reflexos sentidos sobre o Estado - destruição do orçamento estatal, para abrir espaços de acumulação privada - fundos de previdência, privatização, etc., ou seja, as formas de resposta às contradições do processo de acumulação se manifestam por meio de luta de classes e da articulação da burguesia em torno do atendimento dos seus interesses em detrimento do trabalho.

Além disso, estas tentativas também se manifestam por meio da ação dos Estados Nacionais, não apenas dentro de seus espaços nacionais, mas na sua forma de atuação no mundo. Os Estados Nacionais, pressionados pela dificuldade em superar a crise, aliam-se ao seu capital nacional em busca de espaços de acumulação e extração do valor fora de suas fronteiras geográficas, gerando aumento da pressão competitiva e, a nosso ver, recolocando a questão do imperialismo em primeiro plano (Foster 2019).

Ao contrário de períodos anteriores, um dos traços desta competição atual é justamente a entrada de novos Estados, como a China, que avançaram em termos de acumulação produtiva - em um cenário de deslocamento da produção - e que

11 Segundo Choonara (2018), a flexibilização quantitativa consiste em criar dinheiro, por meio dos bancos centrais, e empregá-lo para comprar ativos de bancos e de outras instituições financeiras, por meio da aquisição de títulos do governo de posse do setor privado. Esse processo inunda o sistema bancário de liquidez e eleva os preços dos títulos. 
agora passam a disputar espaços de acumulação de capital fora de suas próprias fronteiras, entrando assim na disputa com os tradicionais Estados Ocidentais.

Embora o tema do imperialismo tenha desaparecido do debate nos anos 1970 (Patnaik 1990, apud Amaral 2012) encoberto pela tese liberal da globalização, mais recentemente vem ganhando destaque. Contrariamente à famosa tese apresentada por Hardt e Negri (2000 apud Amaral, op. cit.) do fim do imperialismo e da força dos Estados Nacionais, diversos autores vêm desconstruindo essa ideia por meio de interpretações próprias sobre o imperialismo nos dias atuais.

Panitch e Gindin (2006), por exemplo, apresentam a ideia de que as teses clássicas do imperialismo não servem para explicar o período recente. No entanto, os autores argumentam em favor da existência de um império informal norteamericano, que tem a capacidade de incorporar os rivais, integrando todas as regiões dentro de um sistema efetivo de coordenação sob sua égide. Não se trata do fim da capacidade de ação dos Estados, mas de forma de dominar através dos Estados, possibilitada pela ampla capacidade imperial norte-americana. (Panitch e Gindin 2006, 2013).

Por outro lado, para Callinicos (2005), a etapa atual do imperialismo, depois da Guerra Fria, seria caracterizada por um mundo multipolar, política e economicamente, com as teorias clássicas do imperialismo recuperando sua capacidade de explicação e com a competição se dando de forma muito mais feroz. Depois de 1989, potências subimperialistas e novos centros de acumulação de capital surgem - embora com apoio do centro - no sentido de acirrar a competição. Para Callinicos, os EUA, embora se mantenham hegemônicos, observam forte competição na esfera econômica, com potencial desestabilizador e rivalidades entre Estados.

Após a crise de 2008, a China, o país que parece subverter a lógica global da grande moderação, sentiu os efeitos da retração econômica mundial, principalmente devido à queda da demanda mundial (Ribeiro e Paraná 2019). No entanto, e apesar da discussão sobre o aumento do déficit e das possíveis bolhas da economia chinesa, seu crescimento continua, cada vez mais, sustentado nos investimentos e na expansão do mercado interno. Além disso, o país vem expandindo investimentos no mundo todo, como na América Latina e no Brasil, inclusive adquirindo recursos primários e por meio da compra de empresas. Ademais, o país vem aos poucos tentando desassociar seu próprio crescimento do crescimento dos EUA, a partir de uma expansão do PIB via consumo interno, diversificação do uso das reservas em dólar para além dos títulos americanos da expansão dos investimentos externos. 
A questão fundamental, nesse sentido, é a compreensão de como a ascensão de novos atores, como a China, influenciam o quadro do imperialismo global, acirrando a competição interestatal. Nesse quadro é essencial compreender a atuação dos Estados Unidos frente as contradições que se apresentam.

Do ponto de vista interno, a crise impõe à economia norte-americana uma série de dificuldades relacionadas a expansão da renda das camadas médias da população. Já do ponto de vista externo, como aponta Fiori (2019), é inegável a postura americana atual, de rompimento com a narrativa liberal que havia assumido desde os anos 1990, pautada no discurso a partir do qual sua política externa seria baseada em ampliação da prosperidade global. A nova doutrina de segurança nacional dos Estados Unidos manifesta claramente sua posição de defender os interesses nacionais lançando mão de instrumentos como a guerra convencional, a guerra híbrida e o papel da moeda.

\section{Interpretação sobre a crise brasileira}

Como compreender a crise brasileira a partir das transformações do capitalismo contemporâneo, ligadas, como dissemos, à crise do "capitalismo tout court" (Chesnais,2016); à disfuncionalidade do capital fictício (Carcanholo 2011); ou ainda ao acirramento da competição interestatal? Quais os impactos dessa configuração para o Brasil? Estas questões certamente não são fáceis de serem respondidas. Aqui pretendemos se não as responder, ao menos tentar apontar alguns nexos lógicos.

A primeira questão a se compreender é que, embora o período de crescimento econômico no Brasil entre 2004 e 2010 tenha refletido a adoção de políticas sociais e de investimento, ele deve ser visto no quadro mundial discutido anteriormente, de "grande estagnação" aliada à expansão dos instrumentos de acumulação financeira. Nesse sentido, vale lembrar a importância que teve o cenário externo de alta dos preços dos produtos primários e a ampliação dos fluxos de capitais para o crescimento brasileiro.

Este perfil do crescimento brasileiro e a situação de melhora do setor externo, mesmo depois da crise, coloca um desafio de interpretação sobre as causas externas da crise, a partir do clássico debate estruturalista, acerca dos limites do desenvolvimento periférico. A melhora da situação externa, amplamente diferente da conjuntura que marcava as economias periféricas nos anos 1980, por exemplo, 
fez com que muitos compreendessem a crise apenas a partir de fatores internos e principalmente ligados à política econômica adotada pelo governo Dilma.

Nesse sentido, o desafio é justamente mostrar que, apesar da melhora da posição brasileira no setor externo — visualizada na ampla formação de reservas — aspectos mais estruturais do capitalismo contemporâneo tiveram papel importante na interrupção do crescimento. Como queremos mostrar, esse impacto se dá, não apenas pela via do comércio, mas, também, pela via financeira e das respostas dos países centrais à crise internacional.

Mesmo crescendo nos anos 2000 com base na expansão do consumo, como aponta Paulani (2009), a economia brasileira esteve fortemente integrada ao circuito de expansão do regime de acumulação com dominância da valorização financeira (Chesnais 1996, 1997 apud Paulani 2009). Nosso crescimento na primeira década do século XXI, portanto, deve ser visto dentro desta perspectiva. Segundo a autora "o consumo não tem dinamismo para puxar a economia, como tem o investimento, e o consumo puxado por crédito não é sustentável no longo prazo, como nos mostra o espelho americano [...] esse arranjo típico de um processo de acumulação em que a finança está no comando, fomentando o crescimento da riqueza fictícia.” (Paulani op. cit., 35).

Dentro deste contexto, a economia brasileira cresceu com base na expansão das exportações de produtos primários, diante do cenário externo de alta dos preços, e via políticas internas de expansão do salário, investimentos e, principalmente, do setor de serviços. Os salários crescem acima da produtividade, já que setores produtivos como o industrial permanecem com baixo crescimento. O cenário externo de demanda pelas exportações, alta das importações, aliado ao dólar baixo e atração de capitais, fizeram com que o aumento dos salários não se refletisse em pressões inflacionárias, permitindo crescimento com aumento de salário (Carvalho 2018).

Nesse sentido, o crescimento brasileiro sempre esteve assentado em uma base frágil, não no sentido de não se refletir em melhoras nas condições de vida, mas por não permitir qualquer mudança estrutural12. Uma das contradições seria exatamente a de que, ao ajudar a contenção da inflação e permitir o acesso barato aos produtos importados, o arranjo brasileiro priorizou o dinamismo interno via consumo e setor de serviços, fragilizando a expansão da indústria.

12 O termo "mudança estrutural" se refere-se à ideia proposta por Prebisch (2000) de que o crescimento deve se dar com transformação da base material da economia, para superar os entraves ao desenvolvimento. 
Com a crise de 2008, as contradições aparecem de forma explícita, apesar das medidas contracíclicas adotadas ainda no governo Lula, no período pós crise, que surtiram algum efeito para evitar a queda do crescimento. Apesar destas medidas, a adoção posterior da chamada Nova Matriz Econômica a partir de 2011, já no governo Dilma, mostra-se absolutamente ineficaz no contexto da nova conjuntura internacional.

O início do governo Dilma foi marcado por uma política macroeconômica mais restritiva, com a queda do investimento público e dos gastos das empresas estatais. A intenção seria uma política fiscal mais rígida, que daria base para uma política monetária mais "frouxa", reduzindo juros e melhorando o câmbio, para que o setor exportador fosse retomado e, também, a indústria. No entanto, o cenário externo estava bastante deteriorado, fazendo com que medidas de interrupção do crédito, queda do investimento e contingenciamento começassem a se manifestar em queda do crescimento. O Banco Central começou a reduzir a Selic já em agosto de 2011 e prosseguiu nesse movimento até outubro de 2012, quando o Brasil atingiu uma taxa básica de juro de 7,25\%. No entanto, não houve retomada do crescimento.

Ou seja, as tentativas de diminuição de juros, mais ajuste fiscal e desonerações, ao invés de promoverem uma retomada do crescimento via expansão do investimento privado, não apresentaram o resultado esperado. Ao contrário, as medidas acirraram a crise, abrindo o período de queda nas taxas de crescimento observadas até então.

A partir de 2015, já no segundo governo, a tentativa de uma política monetária "mais frouxa" é deixada de lado e as medidas de ajuste são ainda mais fortes, incluindo redução de gastos de investimento, aumento de alíquotas de impostos e aumento da taxa de juros para 14,5\%, criando, então, cenário de forte recessão.

Dentro da proposta de compreender esse movimento a partir de causas ligadas às transformações do capitalismo internacional, vamos apontar a existência de dois canais de explicação.

1) Canal de impactos pela via financeira e da resposta dos países centrais à crise:

Embora as medidas adotadas pelo governo Dilma tenham contribuído para aprofundar a recessão, como apontado por Carvalho (2011), as transformações da economia internacional pós-crise de 2008, ligadas ao acirramento das contradições do capitalismo mundial, alteraram profundamente o quadro por meio do qual o breve crescimento brasileiro foi possível. 
Como discutido anteriormente, a crise de 2008 pode ser vista como manifestação da crise capitalista, marcada pela dificuldade em ampliar a taxa de expansão produtiva e pelo recorrente adiamento da resolução da crise, via exacerbação dos mecanismos que levam à expansão da financeirização e, com isso, a novos elementos de crise.

O período posterior à crise de 2008 é marcado justamente pela resposta dos países centrais à crise, via amplo programa de resgate dos bancos, aliado a política fiscal austera e que não conseguiu (e não consegue até hoje) estimular a expansão da demanda agregada via investimentos e emprego. Essa realidade da resposta dos países centrais à crise, somada ao baixo dinamismo destas mesmas economias, fizeram com que o cenário externo mudasse consideravelmente para as economias periféricas.

Como afirma Akyus (2013), o crescimento dos países em desenvolvimento anterior à crise de $2008 \mathrm{fez}$ com que muitos acreditassem na tese de que haveria um descolamento (decoupling) do crescimento do Sul frente ao Norte. A ideia era de que os países em desenvolvimento, ainda que dependendo dos países centrais, teriam encontrado maneiras de crescer independentemente das posições cíclicas dos países avançados, perseguindo políticas domésticas e neutralizando os choques externos. Segundo Akyuz, essa tese desconsiderou o fato de que o crescimento do Sul sempre esteve atrelado ao ciclo do Norte, via não apenas exportações de primários, mas ao boom do fluxo de capitais, crescimento rápido da liquidez internacional e históricas taxas de juros baixas. (Akyuz 2013).

Depois do colapso do Lehman Brothers, em setembro de 2008, o ambiente econômico global se deteriorou em diversos aspectos, que antes haviam sustentado o crescimento no mundo em desenvolvimento, resultando em uma crise acentuada em vários países. Houve rápida recuperação a partir de 2009, resultante de políticas contracíclicas adotadas nas economias em desenvolvimento, dadas as melhores posições fiscais e de balanço de pagamentos durante a expansão anterior. Além disso, a resposta da política monetária à crise por parte dos EUA e da Europa também ajudou a recuperação, direcionando os fluxos de capital de volta para eles após uma parada súbita e reversão acentuada provocada pelo colapso do Lehman (AKYUZ, op. cit). No entanto, essa aparente recuperação não pôde se manter. Já em meados de 2009, a alta nos fluxos de capital e nos preços das commodities terminou e as exportações para os países centrais diminuíram consideravelmente. 


\section{Gráfico 3 - Brasil: Saldo das contas do balanço de Pagamentos (bilhões de dólares, 2000-2017)}

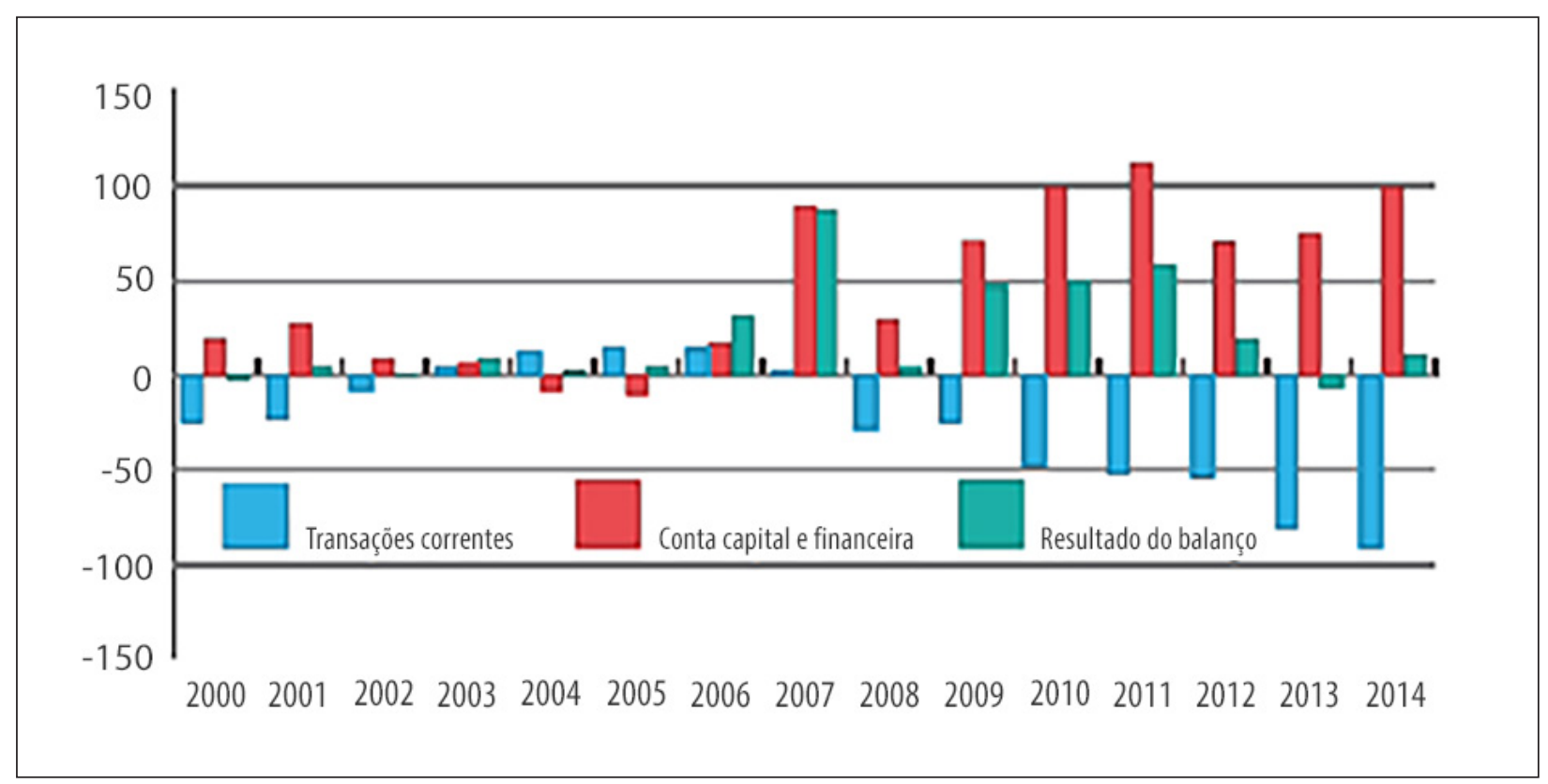

Fonte: Pereira, 2015

Como se observa no Gráfico 3, a crise de 2008, ainda que não gere crise cambial, provoca mudança importante do cenário anterior. A partir de 2011 e 2012 há uma queda na conta de capital e financeira, que reflete mudança no cenário anterior de crescimento dos fluxos de capitais. Aliado a forte crise da balança comercial, desde 2008 registram-se déficits importantes que comprometem o resultado do balanço de pagamentos. Esse movimento levou a uma instabilidade importante da taxa de câmbio brasileira, tendendo a valorização. Esse cenário comprometeu ainda mais o cenário da balança comercial já em crise. Como explica Akyuz (2013),

A crise financeira nos países avançados levou a uma instabilidade considerável dos fluxos de capital privado, dos spreads, dos preços das ações e das taxas de câmbio nos países em desenvolvimento [...] a fuga para a segurança desencadeada pelo colapso do Lehman levou a uma parada e reversão repentinas, resultando em fortes pressões descendentes sobre taxas de câmbio e preços de ativos. A integração mais estreita e profunda com os principais centros financeiros e as crescentes posições de ativos e passivos brutos dos países em desenvolvimento com os países avançados intensificaram a transmissão do estresse financeiro aos mercados de ativos, bancos e moeda. A crise também levou à contração do crédito nos países em desenvolvimento devido ao corte nos empréstimos bancários 
internacionais e nos empréstimos locais por afiliados de bancos estrangeiros nos países em desenvolvimento, bem como no declínio nos empréstimos transfronteiriços interbancários para financiamento pelos bancos domésticos $(\text { AKYUZ, 2013) })^{13}$

Cada país responderá de uma forma a esse novo cenário, dependendo de sua abertura e exposição a economia internacional. Talvez o Brasil não tenha sido o mais afetado, no entanto, embora não tenha provocado uma crise cambial de grandes proporções, a baixa dos fluxos de capitais internacionais aliada à crise na Balança Comercial alterou profundamente o quadro, inclusive político, para as tentativas de adoção de políticas internas de incentivo ao crescimento econômico. A alteração do cenário externo evidencia o quanto a economia brasileira estava atrelada ao crescimento dos países centrais (e emergentes, como a China) tanto no que se refere à Balança Comercial como ao cenário de forte expansão dos fluxos de capitais.

Dentro desse quadro geral, a resposta das economias centrais para a resolução da crise em suas próprias economias impôs novas restrições ao desenvolvimento periférico - via fuga para a segurança, mediante restrição dos fluxos de capitais, que contribuiu para a instabilidade cambial dos países periféricos e para o acirramento da crise do balanço de pagamentos, ainda que não tenha gerado crise cambial de grandes proporções.

Neste cenário seria possível afirmar que as respostas dos países à crise de 2008, ao não conseguirem recuperar a demanda agregada, recompondo as importações e ainda pressionando para a desaceleração de outros países, como a China, tiveram um efeito extremamente negativo para economias periféricas como a brasileira. O cenário externo pós crise, mesmo com atraso em termos de impacto na queda do crescimento brasileiro, acabou exacerbando as contradições do frágil modelo brasileiro.

13 The financial crisis in AEs has led to considerable instability of private capital inflows, yield spreads, equity prices and exchange rates in DCs. [...] the flight to safety triggered by the Lehman collapse led to a sudden stop and reversal, resulting in strong downward pressures on exchange rates and asset prices. Closer and deeper integration with major financial centres and rapidly growing gross asset and liabilities positions of DCs with the AEs intensified the transmission of financial stress to asset, banking and currency markets. The crisis also led to a contraction of credit in DCs due to cut-back in international bank lending and local lending by foreign banks' affiliates in DCs as well as declines in inter-bank cross-border lending for funding by domestic banks (AKYUZ, 2013) 
2) A crise e o acirramento da competição interestatal - mudança do eixo de apropriação do valor do Ocidente para a Ásia

O segundo canal de explicação sobre os impactos das transformações discutidas anteriormente na crise brasileira se relaciona ao acirramento da competição interestatal e à mudança do eixo de apropriação do valor do Ocidente para a Ásia, principalmente a China.

Como discutido anteriormente, a não resolução da crise tem levado a uma dificuldade crescente dos países centrais em retomar os níveis de expansão econômica, com geração de renda para suas camadas médias. Isso tem intensificado os mecanismos de adiamento da crise, via endividamento e financeirização, como também a tendência de que os Estados Nacionais busquem novas fronteiras de acumulação. O quadro sinaliza, nesse sentido, para um aumento da pressão competitiva interestatal, em que se observa uma política externa mais agressiva por parte de alguns países, como os Estados Unidos, por exemplo.

Como visto anteriormente, o pano de fundo desse quadro geral se insere em um quadro maior de crise de sobreacumulação (Chesnais, 2016) ligada, a nosso ver, também a um deslocamento produtivo do capital para novas áreas de valorização. A ampliação da geração e apropriação de valor na Ásia, principalmente na China, promove não apenas o acirramento das contradições no centro do capitalismo, mas também uma dificuldade cada vez maior para que as demais economias periféricas ampliem sua capacidade de geração e apropriação do valor.

Essa mudança histórica deve ser considera como um aspecto essencial que altera profundamente a questão do desenvolvimento periférico com mudança estrutural, nos termos de Prebisch (2000 ), por exemplo. Isto porque a ascensão da Ásia e da China como grandes polos de comércio globais atua de forma a contrabalançar a centralidade norte americana como centro cíclico principal. No caso da China, tem-se uma economia que amplia cada vez mais sua parcela mundial da produção industrial, exportando para o mundo todo e impondo uma série de desafios para a expansão da indústria e da renda em países periféricos. Instaura-se não apenas pressão pela primarização das economias, voltadas ao atendimento da demanda por recursos primários, mas também pressão pela competição com produtos manufaturados de alta produtividade .

Esta nova realidade histórica do capitalismo altera profundamente a ideia de desenvolvimento. O crescimento brasileiro, embora tenha refletido políticas internas fundamentais, teria sido impossível sem a conjuntura de alta dos preços 
dos produtos primários e queda dos preços dos produtos manufaturados baratos da Ásia. A própria possibilidade de expansão do consumo teve relação com essa mudança estrutural da economia global, não apenas no Brasil, mas em diversos países periféricos. Mas, ao mesmo tempo, essa realidade histórica impôs e impõe enormes desafios para o crescimento com mudança estrutural. Assim, em certo sentido, a própria crise brasileira estava sendo adiada, dada a capacidade de manter o crescimento via políticas internas, mas que não se sustentava sem um cenário externo favorável. Com a mudança do cenário externo essas contradições se manifestaram de forma gritante.

\section{Conclusões}

A crise econômica brasileira, que também é uma crise política, representa a inversão de um período de expansão observado entre os anos de vigência dos governos do PT, principalmente do governo Lula. Naquele período, a partir de contexto internacional favorável, foi possível crescer com distribuição de renda e aumento de salários, com resultados fundamentais em termos de redução da pobreza. No entanto, mesmo naquele período de crescimento, já se observavam diversas contradições do modelo que, por sua vez, refletiam contradições do próprio capitalismo contemporâneo.

Como procuramos demonstrar, observa-se atualmente um contexto de acirramento das contradições, que refletem as barreiras e limites de seu próprio movimento de acumulação de capital. O adiamento recorrente da resolução da crise de lucratividade, desde os anos 1970, ampliou os mecanismos de acumulação pela via financeira que, por sua vez, acirrou a contradição entre as promessas de apropriação versus geração de valor. Esse adiamento da resolução da crise leva a mais crises financeiras de grandes proporções, que impõem mais uma vez limitações à expansão econômica.

Ao mesmo tempo, o capitalismo encontrou formas de contornar essa crise, mediante a busca de novos espaços de acumulação, como a Ásia. Se, por um momento, esse movimento foi funcional à continuidade da acumulação, mais recentemente ele trouxe novas contradições, na medida em que, cada vez mais, regiões que geram valor, como a Ásia, tornam-se não apenas um centro de produção, como também de apropriação de valor, exacerbando a disfuncionalidade do capital fictício e impondo amplas contradições às economias ocidentais. Neste 
contexto as economias centrais respondem à sua própria recessão mediante a manutenção de políticas de austeridade que só contribuem para o crescimento lento e pouco dinâmico.

Até 2010 a economia brasileira se inseriu nessa conjuntura de forma benéfica, expandindo suas exportações de produtos primários, importando produtos baratos industrializados e mediante bem-sucedidas políticas internas. No entanto, quando a conjuntura internacional se altera, as contradições vêm à tona e impõem forte retração do crescimento brasileiro.

Com essa interpretação não pretendemos afirmar que as decisões de política econômica do governo Dilma não tiveram papel na crise brasileira. Elas certamente poderiam ter se adequado melhor ao cenário externo. No entanto, nossa interpretação procura dar sentido mais amplo à crise brasileira, procurando compreendê-la dentro de uma unidade de análise mais abrangente. As restrições ao crescimento brasileiro são de ordem estrutural e, como vimos, estão ligados a uma conjuntura de profunda crise econômica e de acumulação global, mas principalmente nas economias centrais.

Estas mudanças implicam novas determinações políticas. Como discutido, quanto mais a crise se acirra nos países centrais, maiores as tentativas de superação via aumento da taxa de exploração do trabalho, sob a forma de diminuição de salários, retirada de direitos, precarização do Estado e, além disso, por meio da busca de espaços de acumulação em regiões periféricas, gerando aumento da pressão competitiva e recolocando a questão do imperialismo em primeiro plano.

Ao contrário de períodos anteriores, um dos traços desta competição atual é justamente a entrada de novos Estados, como a China, que avançaram em termos de acumulação produtiva - em um cenário de deslocamento da produção - e que agora passam a disputar espaços de acumulação de capital fora de suas próprias fronteiras, entrando assim na disputa com os tradicionais Estados ocidentais.

\section{Referências}

Akyuz, Yilmaz. "Waving or drowning: developing countries after the financial crisis”. South Centre, Research Paper, June, 2013. Disponível em: < https://g24.org/wpcontent/uploads/2014/03/RP48_Waving-or-drowning_EN.pdf > .

Amaral, Marisa Silva. “Teorias do imperialismo e da dependência: a atualização necessária ante a financeirização do capitalismo”. São Paulo. Tese de Doutorado, USP, 2012. 
Agarwala, A.N. e Sigh. S.P. (orgs.). "A Economia do Subdesenvolvimento”. São Paulo, SP. Editora Contraponto, 2010.

Boito Jr, Armando. “Governos Lula: A nova burguesia nacional no poder”. In: Boito Jr e Galvão, Andreia. “Política e classes sociais no Brasil dos anos 2000”. São Paulo, SP. Editora Alameda, 2012.

Callinicos, Alex. "Imperialism and global political economy”. United Kingdom. International Socialism, Issue 108, Autumn, 2005.

Carcanholo, Marcelo. "Conteúdo e forma da crise atual do capitalismo: lógica, contradições e possibilidades”. Crítica e Sociedade: revista de cultura política. v.1, n.3, Edição Especial - Dossiê: A crise atual do capitalismo, dez. 2011.

Carvalho, Laura. “Valsa Brasileira — do boom ao caos econômico”. São Paulo, SP. Editora Todavia, 2018.

Chesnais, François. "Finance Capital Today - Corporations and Banks in the Lasting Global Slump”. Brill Academic Pub; Lam edition. 2016.

Chesnais, François. A mundialização do capital. São Paulo. Editora Xamã. 1996.

Choonara, Joseph. "A economia política da grande depressão”. Artigo publicado no n. 158 da revista International Socialism, Abril de 2018.

Corrêa Vanessa Petrelli e Dos santos, Claudio Hamilton. "Modelo de crescimento brasileiro e mudança estrutural - avanços e limites”. In: Corrêa, Vanessa Petrelli (org). “Padrão de acumulação e desenvolvimento brasileiro”. São Paulo, SP. Editora Fundação Perseu Abramo, 2013. Capítulo 1, páginas 17 a 56.

Fiori, Jose Luis. “A síndrome de babel e a nova doutrina de segurança dos Estados Unidos”. Revista Tempo Do Mundo, 4(2), 47-56. 2019. Disponível em: < http:// www.ipea.gov.br/revistas/index.php/rtm/article/view/12 > .

Foster, John Bellamy. “Late Imperialism - Fifty Years After Harry Magdoff's The Age of Imperialism”. Monthly Review, July, 20. 2019.

Guimarães, José Ribeiro Soares. "Perfil do Trabalho Decente no Brasil: um olhar sobre as Unidades da Federação durante a segunda metade da década de 2000”. Brasília, DF. Organização Internacional do Trabalho (OIT), Escritório no Brasil. 2012. 416p. Harvey, David. “Condição pós-moderna”. São Paulo. Edições Loyola; Edição: 25 a 1992. Kalecki, Michal. “Os Aspectos Políticos do Pleno Emprego”. 1944. Disponível em: < http://www.vinc.afbndes.org.br/seriebndes/kalecki.htm > .

Kliman, Andrew. "A Grande Recessão e a teoria da crise de Marx". Revista Outubro. Número 24, Segundo Semestre. 2015.

Marx, Karl. “O Capital - Volume 3”. São Paulo. Abril Cultural. 1984.

Medeiros, Carlos Aguiar de. “Inserção externa, crescimento e padrões de consumo na economia brasileira”. Brasília. IPEA, 2015. 
Medeiros, Carlos Aguiar de "Instituições e desenvolvimento econômico: uma nota crítica ao "nacionalismo metodológico". Campinas, SP. Economia e Sociedade. v. 19, n. 3 (40), p. 637-645, 2010.

Nayyar, Deepak. “A Corrida Pelo Crescimento: Países em Desenvolvimento na Economia Mundial. Rio de Janeiro, RJ. Editora Contraponto, 2014.

OECD DATA. 2020. Base de Dados da OECD. Disponível em: < https://data.oecd.org/ > . Panitch, Leo; Gindin, Sam. The Making of Global Capitalism: The Political Economy of American Empire. Verso, 2013.

Panitch, Leo; Gindin, Sam “Capitalismo global e império norte americano”. In: PANITCH, Leo; LEYS, Colin (ed.). Socialist Register 2004: o novo desafio imperial. Buenos Aires: CLACSO; Londres: Merlin. 2006.

Paulani, Leda Maria. “A crise do regime de acumulação com dominância da valorização financeira e a situação do Brasil”. Estudos Avançados, n. 23 (66), 2009.

Pereira, Lia Baker Valls. "A volta das restrições externas ao crescimento econômico?”. Conjuntura Econômica. FGV, IBRE. Vol. 69 n. 2 Fevereiro 2015.

Pochmann, Márcio. "Nova classe média? O trabalho na base da pirâmide social brasileira”. São Paulo, SP. Editora Boitempo, 2012.

Prebisch, Raúl. "O Desenvolvimento Econômico da América Latina e seus Principais Problemas”. In: Bielshowsky, Ricardo. "Cinqüenta anos de pensamento na CEPAL”. Rio de Janeiro, RJ. Editora Record. 2000.

Ribeiro, Valéria Lopes e Paraná, Edemílson. "Virtú e fortuna: A trajetória da ação desenvolvimentista chinesa e seus desafios contemporâneos”. Revista da Sociedade Brasileira de Economia Política. Número 54 (set 2019 — dez 2019).

Serrano, Franklin e Summa, Ricardo. "Conflito distributivo e o fim da "breve era de ouro” da economia brasileira”. São Paulo, SP. Revista Novos Estudos Cebrap, DOSSIÊ balanço crítico da economia brasileira (2003-2016). Edição 111 - Volume V. 37 N. 2 - Maio-Agosto 2018.

Streeck, Wolfgang. “Tempo Comprado - A crise adiada do capitalismo democrático”. São Paulo. Editora Boitempo, 2018.

Tavares, Maria da Conceição. "A retomada da hegemonia norte-americana”. Revista de Economia Política. Vol. 5. Número 2. 1985.

Torres Filho, Ernani Teixeira. "A crise do sistema financeiro globalizado contemporâneo". Revista de Economia Política, vol. 34, n. 3 (136), pp. 433-450, julho-setembro/2014. WorldBank Database 2020 . World Bank Open Data. Base de Dados do Banco Mundial. Disponível em: < https://databank.worldbank.org/home.aspx > . 